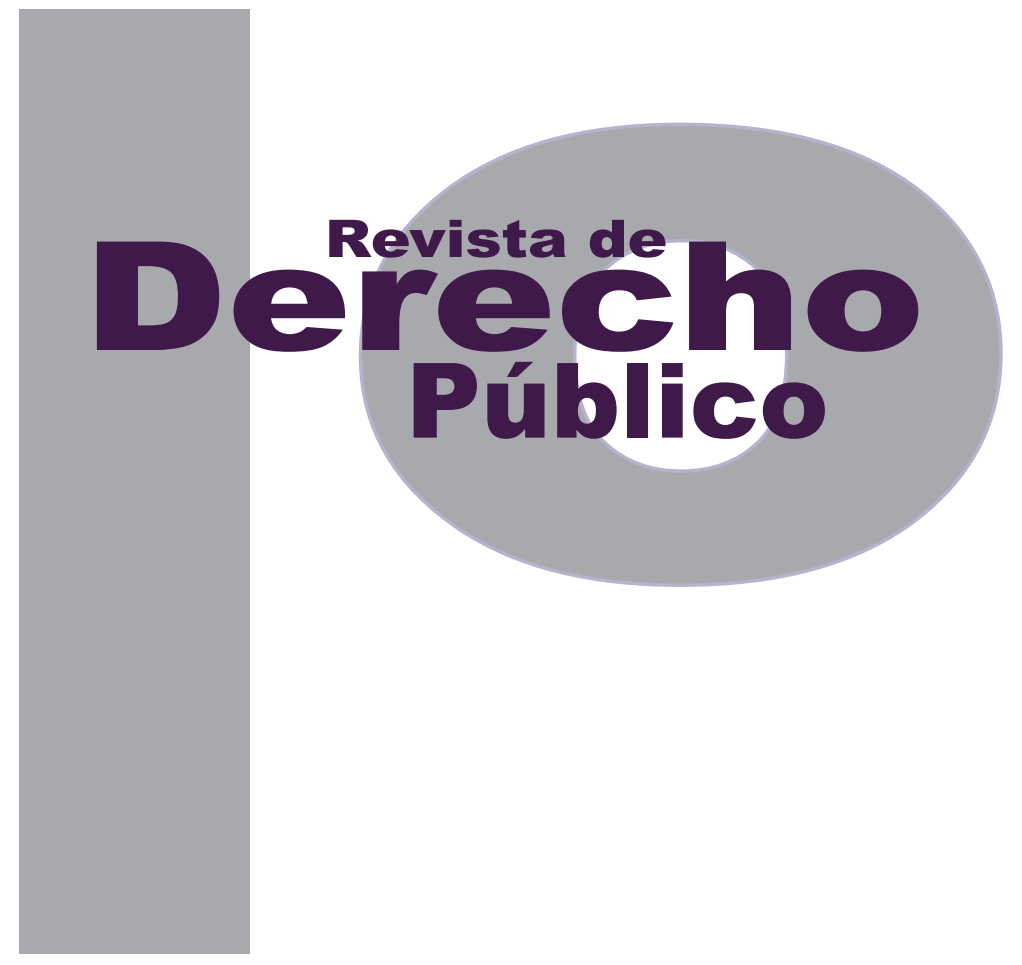

\title{
EL CONCEPTO DE SEGURIDAD JURÍDICA, ELEMENTOS Y AMENAZAS ANTE LA CRISIS DE LA LEY COMO FUENTE DEL DERECHO
}

\author{
FERNANDO ARRÁzOLA JARAMILLO
}

Artículo de revisión

Universidad de los Andes

Facultad de Derecho

Revista de Derecho Público N. ${ }^{\circ} 32$

Enero - Junio de 2014. ISSN 1909-7778 


\title{
El concepto de seguridad jurídica, elementos y amenazas ante la crisis de la ley como fuente del derecho
}

\section{Resumen}

El presente artículo de revisión bibliográfica constituye el primer documento del autor en el programa de Doctorado en Ciencias Jurídicas de la Pontificia Universidad Javeriana, y describe el estado del arte en relación con algunos aspectos que resultan fundamentales para la seguridad jurídica. Para tales efectos, aborda el concepto de esta, su relación con el derecho, sus elementos e importancia, si se la entiende como valor o como principio, al igual que las principales amenazas que sobre ella se ciernen, centrándose en la crisis de la ley como fuente del derecho y en la obligatoriedad del precedente judicial.

Palabras clave: Seguridad jurídica, concepto de seguridad jurídica, elementos e importancia de la seguridad jurídica, seguridad jurídica y el derecho, seguridad jurídica como valor o principio, amenazas a la seguridad jurídica, crisis de la ley, obligatoriedad del precedente judicial.

\section{The concept of legal certainty, elements and threats facing the crisis of legal rules as source of law}

\begin{abstract}
The present paper is a bibliographical overview that constitutes the author's first document presented for his PhD in Law from the Pontificia Universidad Javeriana. It presents the latest studies on certain fundamental concepts regarding legal certainty. For this purpose, it will deal with matters such as the concept of legal certainty and its relation with the legal system, the elements and importance of legal certainty, its perception as a value or as a principle, as well as the main threats to legal certainty, focusing on the crisis of the law as a source of a legal system and the imperativeness of legal precedent.
\end{abstract}

Keywords: Legal certainty, concept of legal certainty, elements and importance of legal certainty, legal certainty and the law, legal certainty as a value or as a principle, threats to legal certainty, crisis of the law, imperativeness of legal precedent.

\section{O conceito de segurança jurídica, elementos e ameaças ante a crise da lei como fonte do direito}

\section{Resumo}

O presente artigo de revisão bibliográfica constitui o primeiro documento do autor no programa de Doutorado em Ciências Jurídicas da Pontifícia Universidade Javeriana, e descreve o estado da arte em relação a alguns aspectos que resultam fundamentais para a segurança jurídica. Para tais efeitos, aborda o conceito desta, sua relação com o direito, seus elementos e importância, se esta é entendida como valor ou como princípio, ao igual que as principais ameaças que sobre ela pairam, centrandose na crise da lei como fonte do direito e na obrigatoriedade do precedente judicial.

Palavras-chave: Segurança jurídica, conceito de segurança jurídica, elementos e importância da segurança jurídica, segurança jurídica e o direito, segurança jurídica como valor ou princípio, ameaças à segurança jurídica, crise da lei, obrigatoriedade do precedente judicial. 


\section{SUMARIO}

Introducción - I. CONCEPTO DE SEGURIDAD JURÍDICA Y SU RELACIÓN CON EL DERECHO - A. Concepto de seguridad jurídica - B. Relación de la seguridad jurídica y el derecho - II. ELEMENTOS E IMPORTANCIA DE LA SEGURIDAD JURÍDICA - A. Elementos o presupuestos de la seguridad jurídica - B. Importancia de la seguridad jurídica - III. LA SEGURIDAD JURÍDICA COMO VALOR O COMO PRINCIPIO - IV. PRINCIPALES AMENAZAS A LA SEGURIDAD JURÍDICA - A. La crisis de la ley y la seguridad jurídica - B. El precedente judicial y la seguridad jurídica - V. CONCLUSIONES - Bibliografía. 


\title{
El concepto de seguridad jurídica, elementos y amenazas ante la crisis de la ley como fuente del derecho ${ }^{1}$
}

\author{
Fernando Arrázola Jaramillo²
}

Introducción

La seguridad jurídica es un concepto que pareciera importar solo a los juristas. Pocos son verdaderamente conscientes de la relevancia de vivir bajo el imperio de un ordenamiento que brinde dicha seguridad, pues las repercusiones, cuando no está presente, pueden ser realmente demoledoras. La seguridad jurídica compromete todo aquello que estimamos parte indispensable de un plan de vida, por lo tanto impacta de manera decisiva no solamente nuestra existencia sino también la de todos quienes nos rodean.

Sin embargo, la seguridad es un término general, complejo y ambiguo, que para efectos de

Cómo citar este artículo: Arrázola Jaramillo, F. (Junio, 2014). El concepto de seguridad jurídica, elementos y amenazas ante la crisis de la ley como fuente del derecho. Revista de Derecho Público, 32.

2 Abogado de la Universidad de los Andes. Magíster en Educación del Centro de Investigación y Formación en Educación (CIFE) de la Universidad de los Andes. Profesor de Derecho Procesal de la misma universidad. Correo: farrazol@uniandes.edu.co este trabajo requiere de algunas precisiones. En primer lugar, rara vez, por no decir jamás, los seres humanos estamos en capacidad de disfrutar de unas condiciones de seguridad plenas y absolutas que nos permitan vivir ajenos a todo temor o sobresalto: desde el momento mismo del nacimiento nos acompañará una dosis de inseguridad. Paradójicamente, esa dosis de inseguridad también tiene aspectos positivos, toda vez que resulta necesaria para evitar el estancamiento y la mediocridad; nos obliga a fortalecernos, a improvisar, a prever, a solucionar, a evolucionar, a sobrevivir, a crecer.

El mundo ha venido cambiando de manera importante, y con él también el derecho. Pasamos de una larga tradición civilista en que la ley era considerada la depositaria del pacto social de los pueblos y la justicia estaba ineludiblemente ligada al cumplimiento de su tenor literal, para encontrarnos ahora en un mundo donde la ley ha perdido gran parte de su valor, y la Constitución, con sus principios y garantías, se ha convertido en la verdadera depositaria del pacto 
social y se ha erigido también en fuente indiscutible y suprema de toda decisión judicial.

El propósito del presente artículo es presentar los resultados de la revisión bibliográfica que se adelantó en relación con algunos temas de la seguridad jurídica, por tratarse de un principio de amplia y extensa significación. Para este fin, se consultó la bibliografía disponible en algunos países de América Latina, ejercicio que incluyó autores argentinos, ecuatorianos, colombianos y chilenos, entre otros, así como autores europeos, principalmente de España y de Italia, y algunos provenientes de ordenamientos jurídicos del common law, la mayoría de ellos correspondientes al siglo XX.

Temáticamente, la revisión bibliográfica de que da cuenta este artículo aborda en primer lugar el concepto mismo de seguridad jurídica y su relación con el ordenamiento jurídico; en segundo lugar los elementos que componen la seguridad jurídica y la importancia de estos, haciendo especial mención a su calidad de valor o de principio, para luego entrar en el asunto más polémico de todos: las amenazas que comprometen la seguridad jurídica, entre las cuales el precedente se destaca sobradamente por lo controversial. Finalmente, se presentan las conclusiones.

El objetivo es hacer un aporte a la literatura jurídica de los países que, como en el caso de CoIombia, conciben la seguridad jurídica como un ideal de difícil concreción, como un deber ser que algún día habrá de erigirse en uno de los grandes pilares del ordenamiento jurídico, venerado y respetado por todos, pero en ningún caso sometido a los avatares del acontecer político y a la conveniencia de los gobernantes de turno.

\section{CONCEPTO DE SEGURIDAD JURÍDICA Y SU RELACIÓN CON EL DERECHO}

La seguridad jurídica es un concepto de una significación tan amplia y de una trascendencia y relevancia tales para cualquier ordenamiento jurídico, que mal haríamos en pretender abordar a profundidad todos y cada uno de los elementos que resultan de su esencia, o que confluyen al mismo tiempo para darle su dimensión integral. En el presente aparte se muestran principalmente los resultados de la revisión bibliográfica adelantada con respecto al significado o dimensión del concepto de seguridad jurídica y a su relación con el derecho.

Antes de continuar es pertinente efectuar dos aclaraciones fundamentales. La primera, poner de presente que la mayoría de los autores consultados se aproximan a la definición de seguridad jurídica a través de sus manifestaciones, de sus elementos, de los requisitos que en su concepto debe reunir un ordenamiento jurídico para que se considere consagrada dicha seguridad, pero solo algunos se aventuran a dar una definición concreta y precisa de ella, tal vez por la dificultad para hacerlo, que de antemano muchos reconocen. La segunda, derivada de la anterior, consiste en que entre las diversas aproximaciones a la definición de seguridad jurídica encontradas, algunos autores la ubican fundamentalmente en la previsibilidad y la cer- 
teza de la actuación del Estado y de los particulares; otros la conciben como la seguridad del derecho mismo (criterio formal), particularmente como una manera de limitar el ejercicio de poder del Estado; mientras otros la entienden como la seguridad que se brinda a través del derecho (criterio material). En resumen, la mayoría de las definiciones contiene una mixtura de algunas o todas las anteriores.

Ricardo García Manrique (2012) da una perspectiva que puede aclarar la anterior clasificación, pues reconoce que hay otros conceptos de seguridad jurídica diferentes del formal. Se trata de un concepto material y de un concepto mixto. En cuanto al material, debe entenderse como la seguridad "respecto de determinados bienes o respecto de la satisfacción de determinadas necesidades realizada a través del derecho; es material en el sentido de que requiere que las normas primarias de un sistema jurídico incluyan determinados contenidos" (p. 201). Y es mixto aquel concepto según el cual la seguridad jurídica se "entiende como la seguridad respecto de un derecho justo" (p. 201).

\section{A. Concepto de seguridad jurídica}

Hechas las anteriores aclaraciones, la revisión bibliográfica del concepto de seguridad jurídica comienza con aquellos que enfatizan la previsibilidad de la conducta del Estado y de los particulares, haciendo referencia primero al derecho español, pues la Constitución de dicho país, en su artículo 9.3, la consagra y garantiza expresamente. En esa línea, resulta especialmente clara y atinada la definición que brinda el Tribunal
Constitucional de España, citado por la autora italiana Aida Kemelmaier de Carlucci (1998, p. 208): "la seguridad es la expectativa razonablemente fundada del ciudadano en saber o poder predecir cuál ha de ser la actuación del poder en la aplicación del derecho".

El autor español José Luis Palma Fernández cita nuevamente al referido Tribunal Constitucional español, cuando precisa aún más el concepto al sostener que la seguridad jurídica "es suma de certeza y legalidad, jerarquía y publicidad normativa, irretroactividad de lo no favorable e interdicción de la arbitrariedad." (1997, p. 43); además, nos da su propia opinión al manifestar que esta consiste, al menos en cuanto a las normas, en conocer cuáles serán las consecuencias que se derivarán de una determinada actuación (p. 38). María Elena Lauroba Lacasa, también española, tiene casi idéntico concepto, pero aclara que incluye conocer la actuación de los poderes públicos que serán los encargados de aplicar esas normas (2002-2003, p. 1248).

El autor colombiano Javier G. Rincón Salcedo (2011, p. 33) concibe la seguridad jurídica fundamentalmente desde una perspectiva formal, pues la considera como "la expectativa que tiene todo operador jurídico de que el marco legal es y será confiable, estable y predecible y como tal, es por sí sola fundamento esencial de la construcción del Estado y del adecuado funcionamiento de la Administración Pública, lo que implica que su consolidación y garantía constituyan uno de los imperativos de actuación para la administración pública de cualquier Estado." Es claro que este autor considera la previsibi- 
lidad de la actuación por parte del Estado un elemento esencial de la seguridad jurídica.

Por su lado, el jurista español Jesús Leguina Villa, citado por Aida Kemelmaier de Carlucci (1998, p. 207), brinda un concepto similar al otorgarle a la seguridad jurídica una triple dimensión como: conocimiento y certeza del derecho, previsibilidad de las consecuencias jurídicas de las conductas y confianza de los ciudadanos en el orden jurídico.

En la misma línea aparece el autor ecuatoriano Miguel Hernández Terán, para quien la seguridad jurídica no solamente consiste en la certeza y previsibilidad de cuáles serán las consecuencias de determinada conducta de acuerdo con el ordenamiento, sino también de que dichas consecuencias se materialicen efectivamente mediante la determinación de la responsabilidad correspondiente (2004, p. 93). Como puede advertirse, para él la seguridad jurídica no solamente depende de la existencia de unas normas jurídicas, sino también de su aplicación efectiva. El brasilero Luiz Guilherme Marinoni (2012, p. 250) comparte con Hernández Terán la previsibilidad de las consecuencias jurídicas de determinadas conductas, pero le agrega un componente importante a la seguridad jurídica al sostener que esta debe ser vista también como estabilidad y continuidad del orden jurídico.

Héctor Belisario Villegas (argentino) comparte integralmente lo que él denomina las "doctrinas actualmente dominantes", que consideran como esencia de la seguridad jurídica "la susceptibilidad de previsión objetiva por los parti- culares de sus propias situaciones jurídicas, de modo tal que puedan tener una precisa expectativa de sus derechos y deberes, de los beneficios que les serán otorgados o de las cargas que habrán de soportar. Así, la seguridad jurídica se expresa prácticamente en la previsibilidad de la actuación estatal" (1993, p. 3).

El tratadista colombiano Álvaro Echeverri Uruburu (2006, pp. 31-32) sostiene, por su parte, que el principio de seguridad jurídica es innominado en la Constitución colombiana, pues en parte alguna de la Carta puede encontrarse mencionado, aunque considera que este, lógica y axiológicamente, se desprende del derecho de acceso a la justicia consagrado en el artículo 229 , teniendo en cuenta que los ciudadanos acuden a la jurisdicción para que les solucione un conflicto mediante un fallo que en algún momento tendrá la calidad de intangible. El principio de seguridad jurídica implica, por un lado, la certeza del derecho en cuanto al conocimiento de cuáles serán las normas aplicables en un caso concreto y, por otro lado, algún grado de seguridad en cuanto a la interpretación uniforme que jueces y tribunales darán a dichas normas, de tal forma que tenga realización el principio de igualdad ante la ley, es decir, que ante situaciones de hecho similares deben seguir pronunciamientos jurisdiccionales similares.

Respecto a lo anterior, William D. Rogers y Paolo Wright Carozza, citados por Kemelmaier de Carlucci (1998, p. 207), aclaran su opinión en cuanto a que la certeza y la seguridad que brinda la seguridad jurídica jamás pueden ser conceptos absolutos, pues en la vida no hay ni pue- 
de existir algo absoluto. De la misma manera, la seguridad jurídica no será una cuestión de si existe o no existe, sino más bien de si estamos en presencia de más o de menos seguridad.

Ahora bien, otros autores tienen una opinión acerca de la seguridad jurídica que, si bien no desconoce la importancia de la previsibilidad de las consecuencias de la conducta del Estado y de los particulares, conciben el concepto en asociación más estrecha con la existencia y la estabilidad de un ordenamiento jurídico, lo cual brinda la seguridad que se deriva precisamente de limitar el poder del Estado.

El primer autor en esta línea de pensamiento es el tratadista español Ricardo García Manrique (2012, p. 194), quien comparte el concepto de Gustav Radbruch al considerar que esta es “'la seguridad del derecho mismo' por contraposición con otras seguridades realizadas a través del derecho", de tal forma que "el objeto de la seguridad es el propio derecho, con independencia de cuáles sean los bienes o intereses que el derecho garantice." Sin embargo, el mismo García Manrique califica esta propia definición como formal, en la medida en que la seguridad jurídica no determina el contenido material del derecho, pues esta "puede predicarse de un sistema jurídico con cualquier contenido material" (p. 199). Según este mismo autor, para Hobbes la seguridad jurídica era entendida como

la seguridad del propio derecho, es decir, la seguridad acerca del contenido de las normas que lo componen y de su correcto funcionamiento. Una vez constituido el Estado de acuerdo con las cláusulas del pacto social, la seguridad jurídica ocupa el lugar del máximo valor o ideal regulativo de la actividad estatal, una posición normativa suprema que deriva de la alta consideración atribuida al derecho, en tanto instrumento principal de garantía de los fines del pacto social (p. 84).

Otro importante autor español consultado, César García Novoa, comparte la concepción de la seguridad jurídica como limitación al poder del Estado, al considerar que esta consiste en la propia existencia del derecho, lo cual constituye en sí una garantía de seguridad (2000, p. 22). Sin embargo, precisa su idea dejando en claro que habla de seguridad jurídica como referencia a un tipo concreto de normatividad, la legalidad, la que a su vez concibe como "un tipo de normatividad destinada a servir de límite al ejercicio del poder público, cuyo fundamento se encuentra en la separación entre el Estado y la sociedad y en la necesidad de un orden jurídico protector de ésta frente a aquél". Ese Estado de derecho del que habla el autor, de corte liberal, es el único que puede garantizar la seguridad jurídica (pp. 26-27).

Para el tratadista colombiano Juan Rafael Bravo Arteaga (2005), el elemento que resulta fundamental en el concepto de seguridad jurídica consiste en "la claridad respecto de los derechos y obligaciones que se derivan de las instituciones legales" (p. 14), lo cual presupone que las reglas que las consagran deben ser aplicadas en caso de incumplimiento. $Y$ agrega: la seguridad jurídica "se traduce en la confianza por la estabilidad de las normas, de tal manera que la actividad humana se pueda planificar con arreglo 
a la ley vigente. Se puede decir que se trata de una razonable certeza estable, sin que implique una petrificación o congelación del Derecho" ( $p$. 14).

Finalmente, el tratadista García Manrique concibe la seguridad jurídica como la "expresión de un sistema jurídico bien dispuesto", lo cual complementa sosteniendo que es "la inspiración de buena parte (si no, en cierto sentido, de todas) las leyes de la naturaleza" (p. 85).

\section{B. Relación de la seguridad jurídica y el derecho}

Ahora bien, en cuanto a la relación que existe entre la seguridad jurídica y el derecho, no puede ignorarse la importancia que los autores le asignan. Todos ellos, sin excepción, reconocen en la seguridad jurídica un fundamento necesario e imprescindible para que cualquier ordenamiento jurídico pueda funcionar, independientemente del contenido material de sus normas.

El tratadista español Ricardo García Manrique presenta, de manera especialmente clara y concisa, su concepto en cuanto a la mencionada relación, atribuyéndole la calidad de valor moral con función legitimadora del ejercicio del poder político a través de normas:

La idea de seguridad jurídica aglutina una buena parte de la historia de los esfuerzos por legitimar el poder político ejercido mediante el derecho. La convicción que late bajo la atribución de valor moral a la seguridad jurídica es, dicho muy simplemente, la de que el gobierno de las leyes es preferible al gobierno de los hombres y, más en concreto, que hay una conexión íntima entre ciertas formas de ejercicio del poder político y la protección de la libertad individual (2012, pp. 19-20).

Para Lauroba Lacasa (2002-2003), la seguridad jurídica tiene una relación íntima con todos los demás principios del derecho, puesto que considera que estos "son expresión del de seguridad jurídica o, desde otra perspectiva, todos ellos son factores que contribuyen a la consecución de una más plena seguridad jurídica" (p. 1248). Otro español, José Luis Palma Fernández (1997), comparte el concepto de Lauroba en cuanto a la relación de los principios del derecho con la seguridad jurídica, dado que considera que esta relación "es la auténtica forma de garantizar su respeto y observancia. La indeterminación del concepto en sí mismo considerado quiebra en favor de la mayor concreción de los aspectos especializados sobre los que se vuelca" (p. 38). Nótese cómo Palma Fernández parte de la indeterminación del concepto de seguridad jurídica para darle vida a su propia opinión.

En conclusión, puede afirmarse: (i) que el concepto de seguridad jurídica contiene tres dimensiones desde las cuales debe ser entendido: como la certeza de la actuación del Estado y de sus agentes, al igual que la de los ciudadanos; como la certeza y estabilidad del derecho mismo, independientemente del contenido material de las normas que integran el ordenamiento; y como la seguridad que resulta del derecho, que deviene de las normas bien dispuestas, y que resulta en una seguridad específica con respecto a algunos o varios bienes jurídicos protegidos; 
(ii) que la seguridad jurídica es un elemento fundamental de cualquier ordenamiento jurídico, y que su relación con el derecho es esencialmente legitimadora y garantista, pues es a través de la seguridad jurídica que los demás principios del derecho se materializan y son garantizados, logrando así un armónico funcionamiento de cualquier sistema legal.

\section{ELEMENTOS E IMPORTANCIA DE LA SEGURIDAD JURÍDICA}

Visto, como está, el origen del concepto de seguridad jurídica e igualmente el pensamiento de diversos autores al respecto, resulta importante abordar ahora el tema de los elementos que hacen posible la seguridad jurídica, los requisitos que deben cumplirse para que pueda predicarse la existencia de este principio, o cuáles presupuestos deben confluir para que en un ordenamiento jurídico pueda tenerse como consagrada la seguridad jurídica. Ese es, precisamente, el objetivo del presente aparte.

\section{A. Elementos o presupuestos de la seguridad jurídica}

Sobre este particular, el autor español Juan Bolás Alfonso (1993) hace una clarísima clasificación que distingue entre los presupuestos objetivos y aquellos que considera de carácter subjetivo. Como presupuesto objetivo de la seguridad jurídica menciona solamente uno que denomina escuetamente "la ley aplicable" y que debe reunir los siguientes requisitos: “1. Que exista una ley aplicable...; 2. Que la ley se pu- blique de forma que sea conocida por todos; 3. Que la ley sea clara...; 4) Que la ley esté vigente y no sea alterada por normas de inferior rango y se aplique a los hechos acaecidos con posterioridad a dicha vigencia...; 5) Que la aplicación de la ley esté garantizada por una Administración de Justicia eficaz..." (p. 43). Y en cuanto al presupuesto subjetivo de la seguridad jurídica nombra también uno: la certeza, que igualmente presupone: “1. La certeza en la aplicación de la ley...; 2. La conciencia ciudadana del predominio de la ley y la confianza en el respeto generalizado de la ley por la efectividad y agilidad de los tribunales en su función de juzgar y hacer cumplir lo juzgado..." (p. 43).

Ahora bien, los dos elementos que menciona Bolás Alfonso resumen de manera concisa y simple los dos aspectos que los demás tratadistas consultados consideran más importantes y recurrentes para que se entienda presente la seguridad jurídica en un ordenamiento, aunque no son los únicos.

El primer autor que comparte con Bolás Alfonso los presupuestos objetivos y subjetivos de la seguridad jurídica es Villegas (1993), aunque no los denomina de la misma manera, pues el aspecto objetivo "está dado por las garantías que la sociedad asegura a las personas, bienes y derechos. Estas garantías deben ser estables, y en cuanto a ellas no debe haber cosas imprevistas" (p. 5). ¿A través de qué mecanismo otorga la sociedad las garantías a las que se refiere este autor? A través de la ley, naturalmente. Y en cuanto al aspecto subjetivo, para Villegas “consiste en la convicción que tiene la persona 
de que está exenta de peligros, daños y riesgos. Sabe a qué atenerse y está dominada por un sentimiento de confianza. Ese sentimiento es lo que le permite proyectar el porvenir, trabajar y ahorrar" (p. 5). En otros términos, lo que Bolás Alfonso denomina la certeza, para Villegas es la convicción o la confianza.

Otro autor que da una especial preponderancia a la ley como factor o elemento de seguridad jurídica es el germano Torsten Stein (1997), quien enfatiza en la claridad de la ley para el ciudadano como factor fundamental de la seguridad, pues "sólo entonces es previsible para él la actuación estatal. La intención del legislador, en consecuencia, debe ser reconocible" (p. 12). Además, la ley no solamente debe ser clara sino que también debe gozar de una permanencia en el tiempo, lo que denomina "protección de la confianza", pues supone que el ciudadano pueda confiar en la subsistencia de las leyes (p. 16). $Y$ finalmente, considera que dichas leyes deben regir a futuro y no afectar situaciones consolidadas en el pasado, pues una circunstancia tal afectaría de manera severa la confianza al efectuar "una nueva evaluación de hechos situados en el pasado" (p. 16).

El argentino Atilio Aníbal Alterini (1993) enfatiza también en dos componentes de la seguridad jurídica: la "certidumbre" y la "estabilidad" del derecho, haciendo énfasis igualmente en el componente legislativo del cual se derivan todos los anteriores. En cuanto a la certidumbre del derecho, considera que esta "supone la existencia de normas jurídicas ciertas de las que resultan los derechos de los que es titular la persona, y su consiguiente convicción fundada acerca de que esos derechos serán respetados" (p. 28); y en cuanto a la estabilidad del derecho, se refiere especialmente al formalismo del procedimiento legislativo que debe prevalecer, pues la seguridad jurídica es resultado de "la existencia de un sistema legislativo debidamente ordenado y que prevé el cumplimiento de determinados recaudos para modificar las normas jurídicas: el órgano que dicta esas normas debe tener competencia suficiente, y sujetarse a procedimientos reglados" (p. 39).

Por su lado, Jorge W. Peyrano (también argentino) considera como requisitos indispensables de la seguridad jurídica la claridad de las normas y la estabilidad de estas en el tiempo, aunque agrega otros factores que a su juicio deben confluir para que se entienda presente la seguridad jurídica; el funcionamiento adecuado, confiable y constitucional de los poderes del Estado; la predictibilidad de las consecuencias de las acciones propias y ajenas; el respeto por los derechos y situaciones adquiridas; al igual que la proscripción del 'error iuris' como excusa válida (1998, p. 390). Nótese que este autor comparte la preocupación de Stein por el elemento de la retroactividad de las normas jurídicas, pues considera que esta afecta derechos y situaciones jurídicas ya consolidadas.

De la misma manera, la chilena Mónica Madariaga Gutiérrez hace referencia a algunos elementos que considera fundamentales para la existencia de la seguridad jurídica, entre los cuales menciona especialmente: una ley preexistente que sea aplicada de manera absoluta 
y que no sea retroactiva, la existencia de normas autorreguladoras para la creación del derecho, sujeción del órgano público a las normas jurídicas (Estado de Derecho), al igual que el reconocimiento de la cosa juzgada y la prescripción (1993, p. 35).

Finalmente, para Miguel Hernández Terán (2004) es claro que el cumplimiento de la norma es fundamental para que haya seguridad jurídica, y vincula necesariamente la seguridad jurídica con los valores intrínsecos en las normas, lo cual explica que se refiera a dicha seguridad como un valor. Además, agrega, el valor fundamental que debe estar inserto en las normas es la justicia, lo cual aclara plenamente cuando dice que "de lo anterior se colige con claridad que si la norma jurídica, si la Ley no materializa el valor justicia el legislador se convierte en un factor de quiebra de la seguridad jurídica" (p. 96). En otras palabras, la seguridad jurídica depende no solamente del cumplimiento formal de la norma jurídica, sino también de su coherencia con los valores y principios que la inspiran (p. 95).

De lo anterior resulta necesario concluir que existen dos elementos que, de una u otra manera, los autores consideran fundamentales para que pueda hablarse siquiera de la existencia de la seguridad jurídica. El primero consiste en la existencia de unas reglas claras, estables y que se apliquen a futuro, de tal forma que todos los asociados tengan claridad sobre cuáles son sus derechos y deberes; dichas reglas, naturalmente, se encuentran plasmadas en las leyes y demás normas jurídicas. El segundo es la certeza en el cumplimiento y en la aplicación de las nor- mas, de modo que las consecuencias en ellas establecidas, en caso de incumplimiento, tengan materialización en la realidad.

\section{B. Importancia de la seguridad jurídica}

La importancia de la seguridad jurídica para la existencia y correcto funcionamiento de un Estado no puede soslayarse. Para unos autores es tal que la constituyeron en razón fundamental para justificar la obediencia al derecho; para otros resulta esencial para la existencia misma del Estado de derecho, mientras que otros más la consideran un principio que permea todos los demás principios del ordenamiento jurídico y les garantiza su existencia. Cualquiera de estas aproximaciones resalta de manera suficiente cuán importante es la seguridad jurídica en un Estado de derecho moderno.

García Manrique (2012), quien se ocupa del tema con relativa profundidad, interpreta a Hobbes al entender la seguridad jurídica como el valor último que justifica la obediencia al derecho, aunque siguiendo la línea del criterio material antes mencionado, dicha justificación es válida.

sólo en tanto que la seguridad jurídica designe la seguridad de la vida, de la propiedad, de la libertad y de la igualdad de los ciudadanos garantizadas en la mayor medida posible a través del derecho positivo; en tanto designe nada más la certeza del derecho, o la posibilidad de predecir la acción de los agentes públicos, o la capacidad de saber a qué atenerse, se trata de un valor instrumental, que se corresponde con el carácter instrumental (artificial) que Hobbes atribuye al derecho y al estado (p. 87). 
Cita también a Felipe González Vicén, filósofo del derecho español, quien comparte igualmente la función legitimadora del derecho que cumple la seguridad jurídica, lo que deriva naturalmente en una justificación al deber de obediencia al derecho (p. 22). Sin embargo, en opinión del mismo García Manrique, el origen democrático y el contenido justo de las normas jurídicas son dos razones adicionales para justificar la obediencia al derecho. Ambas razones han sido cuestionadas en mayor o menor medida, luego la seguridad jurídica cobra relevancia al momento de determinar si las normas deben o no ser acatadas (p. 24). En cuanto a la relevancia de la seguridad jurídica como elemento justificante de la obediencia al derecho, Germán Valdés (2003) parece compartirla integralmente, pues considera que "se vive, más que para ser libre o igual a otros mejor posicionados, para tener la seguridad de una respuesta a las exigencias de la vida, para superar la incertidumbre de cómo podrán enfrentarse las necesidades de cada día" (p. 17).

La importancia que Valdés atribuye a la seguridad jurídica en la vida cotidiana encontró eco en el argentino Gregorio Badeni, quien según cita de Kemelmaier de Carlucci (1998), sostiene que cuando los efectos jurídicos de las normas operan irremediablemente es posible "organizar la vida individual y social, sin quedar sujeta a la arbitrariedad y a los cambios normativos injustos, irrazonables e imprevisibles" (pp. 212213). Alterini (1993) se muestra de acuerdo con Badeni en cuanto a que la seguridad jurídica permite organizar la vida de las personas, pues "cada uno tiene derecho - porque es justo- a vivir, a disfrutar de los bienes, a negociar, con leyes tendientes a evitar que se cometan transgresiones, y que sean efectivamente aplicadas por los jueces; con leyes iguales para todos que especifiquen con claridad qué se puede hacer y qué está impedido; con leyes que tengan cierta estabilidad. Sólo cuando se da todo eso hay seguridad jurídica" (p. 11).

Por otro lado, Marinoni (2012) considera que la seguridad jurídica es un "subprincipio concretizador del principio fundamental y estructurador del Estado de Derecho" (p. 250), y de acuerdo con Wingfield, un Estado de derecho "establece principios que limitan el poder del Gobierno al fijar reglas y procedimientos que prohíben la acumulación de poder autocrático u oligárquico... al igual que protege los derechos de todos los miembros de la sociedad. Además, provee un medio para resolver disputas de manera no violenta que establece una paz y una estabilidad duraderas" (p. 232). [Traducción del autor].

De esta manera, para los autores citados, sin seguridad jurídica no resultaría posible hablar de un Estado de derecho, de ahí su fundamental importancia.

En síntesis, la seguridad jurídica no solamente resulta un principio fundamentador del Estado de derecho y un cimiento necesario para todos los demás principios que lo componen, sino que además constituye uno de los argumentos esenciales que pueden presentarse para justificar la obediencia al derecho. Además, la seguridad jurídica hace posible que los bienes que más preciamos se materialicen, tales como la vida, la libertad, la igualdad, la propiedad y otros, sin los 
cuales no parecería viable la existencia tal como la hemos conocido hasta ahora.

\section{LA SEGURIDAD JURÍDICA COMO VALOR O COMO PRINCIPIO}

De la revisión bibliográfica efectuada resultó palpable cómo los diferentes autores consultados hacían referencia a la seguridad jurídica como un principio o como un valor. Independientemente de la trascendencia que el lector quiera asignar a la anterior distinción o de la relevancia práctica de esta, resulta pertinente reflejar en el presente artículo los resultados obtenidos en ese aspecto, los cuales pueden llegar a tener implicaciones importantes al momento de profundizar en el estudio de la seguridad jurídica.

La presente discusión tiene clara relevancia, pues como bien lo plantea el tratadista García Novoa (2000),

la disyuntiva acerca de si la seguridad es principio o es valor puede tener su importancia si se propugna entre valores y principios una distinción más o menos radical, como se ha venido haciendo por un cierto sector de la doctrina. Así, frecuentemente al valor no se le reconoce aplicabilidad directa sino -en palabras de Sa Gomes- una virtualidad meramente invocativa, por su esencia supra positiva. Las normas jurídicas simplemente se inspirarán en ellos aunque no los desarrollarán, entendiendo por desarrollo el despliegue en el ordenamiento jurídico de lo que de una manera más concentrada ya se encuentra en él. A los valores se les tendrá en cuenta a los simples efectos de su condición de parámetros de crítica de las normas positivas. Por el contrario, el principio tendría una función normativa que sería una consecuencia lógica de su identificación con la norma. Los principios, admitida su raigambre positivista, deben ser considerados normas, aunque normas enunciadas con una extrema generalidad, por lo que la diferencia con el resto de disposiciones estaría en un distinto grado de abstracción (p. 34).

Lo que García Novoa hace en la anterior cita es poner la discusión en su punto preciso, pues si la seguridad jurídica se considera un valor, esta no tendría carácter normativo sino simplemente una función inspiradora de los principios y de las demás normas del ordenamiento, mientras que de considerarse un principio tendría desarrollo normativo en distintos niveles del ordenamiento. Así, aunque esta distinción parece haber perdido importancia en la doctrina, que tiende a equipararlos, puede verse una diferencia importante. Los autores que no consideran la seguridad jurídica como un valor, se refieren a ella como un principio. Son estas las dos posiciones predominantes.

Para comenzar, resulta necesario poner de presente el significado tanto del término "valor" como del término "principio", aclarando que no se abordará a profundidad este tema desde el punto de vista de la ética o de la filosofía del derecho, pues dicho estudio abarcaría, por su extensión y profundidad, un espacio que con creces supera el destinado para el presente artículo. Sin embargo, sí se intentará una definición elemental de ambos conceptos y, además, se dejará plasmado cuáles de los autores consultados lo tienen por lo uno y cuáles por lo otro. 
Por elemental y clara se comparte la definición de Madariaga Gutiérrez (1993) cuando define valor como "la calidad que poseen algunas realidades, Ilamadas bienes, por lo cual son estimables" (p. 18). Por su parte, Anthony Weston (2002) considera que valores son "aquellas cosas que nos importan; aquellas metas o ideales a los que aspiramos y con respecto a los cuales nos medimos tanto a nosotros mismos como a los demás" (p. 3). ${ }^{3}$ A renglón seguido, el mismo autor nos da su definición de valores morales, que en su concepto son una categoría específica de valores "que le dan voz a las necesidades y expectativas legítimas de otros y de nosotros mismos" (p. 3). ${ }^{4}$ Ahora bien, en cuanto a dichos valores morales, la autora Ángela Uribe (1998) aclara que las proposiciones morales se reconocen como tales porque en las mismas pueden evidenciarse con frecuencia predicados como "bueno" o "malo", de manera tal que cuando "algo sea moral o extramoralmente bueno o malo, remite con frecuencia a normas. Una norma, entonces, cumple la función de ser una especie de indicador para la acción" (pp. 117-118). Naturalmente, al emplear categorías como bueno o malo para referirnos a los valores, entramos necesariamente en el campo de los juicios de valor, terreno complicado y subjetivo como el que más.

Resta por descubrir qué debe entenderse por "principio", especialmente en cuanto se relaciona con las cuestiones jurídicas de las que se ocupa este escrito. De acuerdo con la definición

3 Traducción del autor.

4 Traducción del autor. que da Cavanellas (1986) en su Diccionario Enciclopédico de Derecho Usual, la palabra "principio" significa “máxima, norma guía." Y en el Diccionario Jurídico Espasa, los "principios generales del derecho" se encuentran definidos como "criterios fundamentales que informan el origen y desenvolvimiento de una determinada legislación que, expresados en reglas y aforismos, tienen virtualidad y eficacia propias con independencia de las normas formuladas en el plano positivo" (Fundación Tomás Moro, 2007). Entendido el término de esta manera, resta por ver si la seguridad jurídica encaja en el concepto de principio, o si más bien guarda más estrecha relación con los valores del ordenamiento.

El primer autor que merece la pena mencionar, entre otras cosas por ser el único que trata el tema con relativa profundidad, es nuevamente el tratadista Ricardo García Manrique, quien, a pesar de no atribuir a la seguridad jurídica valor moral, hace un resumen de los argumentos en la doctrina a favor y en contra de esta presunta calidad de la seguridad jurídica, posiciones de la mayor importancia para este escrito, sin dejar de lado los planteamientos que al respecto exponen los demás autores consultados.

En cuanto a los argumentos que se han esgrimido en la doctrina a favor del valor moral de la seguridad jurídica, García Manrique (2012) menciona con especial énfasis los siguientes:

El primero hace relación a la justicia material, y se resume en el siguiente planteamiento: “La justicia material tiene valor moral; la seguridad jurídica implica, permite o favorece de algún 
modo la realización de la justicia material; luego la seguridad jurídica tiene valor moral" (p. 242). Este argumento, por supuesto, se encuentra cimentado en otros presupuestos sin los cuales no podría sobrevivir, como por ejemplo que la seguridad jurídica forma parte de la justicia material, que la seguridad jurídica tiene valor moral cuando el derecho es materialmente justo, que tiene valor moral porque garantiza el orden social, y que la seguridad jurídica predispone o facilita la justicia material (p. 273).

El segundo argumento tiene que ver con la autonomía individual, pues el autor en comento considera que existe un vínculo entre la seguridad jurídica y la autonomía individual, y entiende la autonomía como "la capacidad de un individuo para orientar significativamente su vida de acuerdo con sus propias decisiones" (pp. 273274). Además, reconoce que la autonomía "está casi unánimemente considerada como un ideal moral del más alto rango" (p. 276). Es preciso mencionar que el anterior concepto se conoce en Colombia bajo el nombre de "libre desarrollo de la personalidad", y es considerado uno de los derechos constitucionales fundamentales. Si bien hay autores que acogen el argumento de que la seguridad jurídica es condición suficiente de la autonomía, cuestión por demás discutible, otros la estiman una condición necesaria más no suficiente de esta (p. 276).

El tercer argumento de García Manrique a favor del valor moral de la seguridad jurídica hace referencia al respeto por la justicia formal, entendida por él como la aplicación consistente y regular de las normas jurídicas vigentes: "la jus- ticia formal tiene valor moral en algún sentido; pero la generación de seguridad jurídica exige el respeto de la justicia formal; luego la generación de seguridad jurídica tiene valor moral en algún sentido" (p. 289). De acuerdo con el autor, entonces, la justicia formal es un elemento que resulta necesario para que pueda predicarse la existencia de la seguridad jurídica (p. 297).

El último argumento que nos brinda García Manrique, en relación con la teoría del valor moral de la seguridad jurídica, es el que denomina automoralidad de la seguridad jurídica, o en otras palabras, que la seguridad jurídica "tiene un valor absoluto, autónomo o intrínseco, en el sentido de no derivado de ningún otro valor moral" (p. 322).

El filósofo del derecho español, Felipe González Vicén, citado igualmente por García Manrique, considera evidente que la seguridad jurídica es efectivamente un valor, de manera que lo que resta preguntarse es si este tiene un carácter absoluto y supremo: "la seguridad jurídica (...) es un valor inmanente al derecho, y lo es, porque establece la certeza en las relaciones sociales y verifica uno de los fines esenciales del derecho, que es el aseguramiento de las relaciones humanas en la convivencia" (p. 29).

García Novoa (2000, p. 33) comparte este concepto de la seguridad jurídica como un valor, pues "si el Estado de Derecho ha de entenderse como un Estado de valores..., no cabe duda que la seguridad es un valor, precisamente porque es un principio básico del ordenamiento." Valdés también comparte la connotación que tiene 
la seguridad jurídica como valor, pero va más allá y lo eleva a una categoría suprema dentro de la escala de valores de una sociedad, ya que “irradia sus proyecciones en todos los ámbitos de la actividad humana, pues sencillamente es la que determina los rumbos que, adoptados por los individuos, garantizan el reconocimiento de sus derechos" (2003, p. 18).

Varios autores más consideran la seguridad jurídica como un valor. Lauroba Lacasa (20022003), aunque reconoce que el preámbulo de la Constitución española contempla la seguridad como "principio inspirador de todo el ordenamiento", lo considera "uno de los valores del ordenamiento jurídico español, esto es, como un fin del ordenamiento" (pp. 246-247). Para Bolás Alfonso es un valor de toda sociedad democrática (1993, p. 42) y Hernández Terán encuentra que "la seguridad jurídica no es sólo un valor declarativo sino también un valor operativo" (2004, pp. 19-20). Villegas considera también la seguridad jurídica como un "valor esencial sin cuya presencia difícilmente puedan realizarse los restantes valores de superior jerarquía" (1993, p. 11).

Ahora bien, hay otra corriente significativa de la doctrina que considera que la seguridad jurídica es un principio del ordenamiento. Encabeza la lista de dichos autores el mismo García Manrique, para quien la seguridad jurídica "no es un valor moral, o no tiene valor moral 0 , para ser más preciso, que los argumentos disponibles a favor de la moralidad de la seguridad jurídica no resultan suficientes" (2012, p. 190). Sin embargo, reconoce que las acciones humanas, las normas y las instituciones pueden ser analizadas desde el punto de vista moral si favorecen los intereses de todos (pp. 192-193).

Por su parte, Stein considera que la seguridad jurídica es un "principio constitucional no escrito, que es derivado del principio de Estado de Derecho" (1997, p. 8), vínculo estrecho que comparte García Novoa aunque cree que su "positivización resulta menos imprescindible, pues el mismo se deduce de la propia esencia de un Estado de Derecho donde prevalezcan los valores frente al legalismo" (2000, p. 37). Bravo Arteaga, igualmente lo considera un principio jurídico fundamental, aunque subordinado a la justicia" (2005, p. 11).

Finalmente, haciendo referencia al derecho comunitario europeo, Jurgen Basedow (1998) explica que la seguridad jurídica "pertenece a los principios generales del derecho no escritos elaborados por la Corte Europea desde el comienzo para la interpretación y complementación del derecho comunitario escrito" (p. 298), para luego rematar afirmando que dicha Corte “ha introducido el tópico de la seguridad jurídica como principio general en su jurisprudencia, y lo ha transformado en una norma jurídica con carácter de cláusula general” (p. 306).

Resulta importante mencionar que hay una tercera posición, aunque minoritaria, la cual considera que, aunque la seguridad jurídica no es precisamente un valor, a través de esta es que pueden materializarse todos los demás valores del ordenamiento. Entre los autores estudiados que comparten esta posición se destacan Mada- 
riaga Gutiérrez, para quien el derecho "permite, por su intermediación, la realización de valores, es decir, que sirve para que valgan otras cosas por él y a su través" (1993, p. 27). En la misma línea, Alterini opina que el derecho, "en cuanto representa un medio para la realización de los valores en la persona individual, sólo puede llevarse a cabo donde existe seguridad jurídica" (1993, p. 20).

En síntesis, la discusión con respecto a si la seguridad jurídica es un valor tan solo inspirador de las normas positivas del ordenamiento, o si se trata de un principio que tiene materialización normativa y desarrollo en diversas disposiciones a diferente nivel en el ordenamiento, concluye en que si bien no existe un consenso en cuanto a su naturaleza, hay dos posiciones claras y mayoritarias frente a su posición en el ordenamiento jurídico: la primera le da un valor supremo y la segunda lo considera uno de los principios tutelares de este. Hay, como se dejó expuesto, otra teoría que le asigna a la seguridad jurídica una calidad intermedia como valor instrumental, pues a través de ella pueden materializarse todos los demás valores de un ordenamiento jurídico.

\section{PRINCIPALES AMENAZAS A LA SEGURIDAD JURÍDICA}

Cuando de un ordenamiento jurídico no se desprende la certeza de las normas y de su aplicación, o la previsibilidad de la actuación tanto del Estado como de los particulares, lo que resulta necesariamente es un estadio en el cual predomina la inseguridad jurídica.
Entre las variadas causales que se han identificado como responsables de afectar la seguridad jurídica se cuentan: el irrespeto a la división de poderes por parte de los funcionarios públicos, las actuaciones del Ejecutivo que pretenden impacto social pero que contradicen el texto de las normas legales, los funcionarios del Estado que ignoran los precedentes judiciales, la invasión de la órbita de competencia de las otras ramas del poder por parte de los jueces, por ejemplo. Sin embargo, parece haber consenso entre los autores en cuanto a que las mayores amenazas a la seguridad jurídica pueden ubicarse en el campo de las leyes, ya sea por una excesiva producción legislativa o por una legislación que es contradictoria, así como también en el campo de la jurisprudencia, especialmente girando alrededor del espinoso tema del precedente judicial.

Existe, además, otra gran amenaza que se ha identificado y que algunos denominan la constitucionalización del derecho, entendida esta como la tendencia a decidir todas las cuestiones jurídicas no con base en las normas legales preexistentes que regulan cada materia, sino en los principios constitucionales que, a juicio de cada fallador, se encuentran inmersos en cada caso, dando así campo a un nivel de incertidumbre con respecto a la actuación discrecional del juez, que parece atentar severamente contra la seguridad jurídica. Sin embargo, por su complejidad y extensión, este aspecto no se trató en el presente escrito.

De esta forma, y reconociendo de antemano la relevancia de todos los anteriores factores como amenazas a la seguridad jurídica, a con- 
tinuación se abordan solamente los problemas derivados de la ley y de la jurisprudencia, concretamente del precedente, reservando los demás para un futuro trabajo.

\section{A. La crisis de la ley y la seguridad jurídica}

Son varios los autores que se refieren a este tema, aunque muy pocos han profundizado en él. Entre quienes sí lo han hecho está el conocido autor español Eduardo García de Enterría, quien explica por qué lo que él denomina "crisis de la ley", se ha convertido en un factor de inseguridad jurídica.

De acuerdo con dicho autor, dos fenómenos han afectado esa condición privilegiada que ha tenido tradicionalmente la ley. Por un Iado, la preeminencia e importancia de unas disposiciones supralegales, que son nada menos que la Constitución de un Estado y, por otro, la desvalorización como consecuencia de una "inflación desmedida de leyes", desarrolladas a su vez por múltiples normas reglamentarias que las complementan o aclaran. Estas normas o reglamentos se encuentran "en estado de perpetua ebullición y de cambio frenético” (1999, pp. 46-47).

El tratadista colombiano Hernando Yepes Arcila plantea el interrogante de cuál es el lugar y el papel que le corresponde a la ley en los sistemas jurídicos contemporáneos, para luego responder que en el Estado social "el rango de la ley dejó de ser supremo y el del legislador dejó de ser exclusivo", mientras que el Estado Constitucional de nuestros días, organizado como Es- tado social de derecho, "clarifica su posición en el sistema de fuentes sometiendo a unos y otros a su imperio indisputable" (2012, p. xiII). Según el tratadista argentino Rodolfo Luis Vigo, ese Estado de Derecho Constitucional, si bien goza del respaldo de los juristas y de la comunidad en general, no está exento de problemas pues "Io anima una cierta lógica difícil de controlar o limitar que puede llegar a un desequilibrante predominio del poder judicial, incluso algunos identifican que desde el EDC se ha ido consolidando un nuevo Estado de Derecho Judicial" (2012, p. 45).

Para Carnelutti, citado por Kemelmaier de Carlucci (1998), la crisis de la ley se ha producido por fenómenos similares, entre los cuales menciona no solamente el excesivo número de leyes, sino también el permanente cambio en estas y el hecho de que la gente ya no respeta las normas legales. Lo peor, agrega, "es que tampoco la acatan quienes son responsables de su interpretación, aplicación y ejecución" (p. 211). Sin embargo, para Carnelutti (1959) la crisis de la ley tiene otra causa de la que no se habla tanto: la mala calidad de las leyes como consecuencia de que estas "se hacen en los parlamentos, y hoy los parlamentos, más todavía con el sufragio universal, no se componen únicamente de juristas" (p. 12).

Para Hernández Terán también presenta una amenaza para la seguridad jurídica la escasa permanencia de las leyes en el tiempo (2004, p. 31), mientras que para Victorino Magatiños Blanco, citado por Kemelmaier de Carlucci, resulta un verdadero problema el que "Ios legisla- 
dores enmiendan o derogan la legislación vigente sin identificar las normas enmendadas o derogadas" (1998, p. 211). Finalmente, el jurista colombiano Luis Fernando Álvarez Londoño S. J. comparte plenamente el efecto nocivo de los repetidos cambios legislativos que se presentan, pues "la distancia entre una reforma y otra, tiende a estrecharse y aun a desaparecer, y así, no es insólito que en la práctica, cada año tengamos que enfrentarnos a nuevas y dispersas decisiones en la materia" (2011, p. 11). Todos Ios anteriores factores afectan de manera importante la certeza y la estabilidad, dos elementos centrales de la seguridad jurídica.

En síntesis, los autores consultados coinciden en que la ley está atravesando actualmente por una evidente crisis que afecta la seguridad jurídica, y que dicha crisis tiene diversas causas, todas identificables, entre las que se destacan la excesiva cantidad de normas que emanan del legislativo, su corta duración en el tiempo como resultado de los permanentes cambios normativos, la incertidumbre en cuanto a la vigencia, la deficiente calidad, así como el fenómeno de la constitucionalización y judicialización del derecho, tema que no es objeto de estudio en este escrito pero sobre el cual se hacen algunos comentarios a continuación.

\section{B. El precedente judicial y la seguridad jurídica}

Este tema ha desatado amplias y encendidas polémicas entre los tratadistas del derecho. El asunto no es de poca monta, pues se trata fundamentalmente de determinar qué tan obligato- rias resultan las decisiones judiciales proferidas por los órganos superiores de la Administración de Justicia, tanto para ellos mismos como para los jueces de inferior jerarquía. La solución que a este trascendental asunto se le brinde tendrá un efecto determinante en la seguridad jurídica, en la medida en que la certeza que a esta le otorga se funda de manera importante la previsibilidad que pueden tener las decisiones de los jueces al resolver asuntos particulares.

Resulta necesario comenzar respondiendo a la pregunta: ¿qué debe entenderse por precedente judicial? MacCormick y Summers lo definen como "decisiones anteriores que sirven como modelos para decisiones posteriores. Aplicar las lecciones del pasado para resolver los problemas del presente y del futuro es una parte básica de la razón práctica del hombre" (1997, p. 1). ${ }^{5}$ Hanna (1957, p. 367), por su parte, aclara que en derecho anglosajón al hablar de precedente se refieren al término stare decisis, "o, en su forma completa, stare decisis et non quieta moveré es generalmente traducido como 'atenerse a (o adherir a) decisiones y no molestar lo que está acordado'”6 ¿Cuál sería, entonces, la alternativa al stare decisis? El mismo Hanna lo resume de manera directa: “(1) Absoluta discreción por parte de una corte para decidir cada caso sin hacer referencia a precedente alguno; o (2) Completa codificación de nuestra ley, con la exigencia de que cada corte busque en el 
código el fundamento de la decisión" (1957, p. 368).

Ahora bien, como no toda decisión judicial crea un precedente, la pregunta que naturalmente surge es: ¿cuándo puede decirse que se crea un precedente judicial? Hanna mismo contesta: "donde una corte toma una decisión que contiene en sí misma un principio, está creando un precedente judicial" (p. 370). ${ }^{7}$

Otra precisión que resulta necesaria en este escrito consiste en clarificar por qué las palabras "jurisprudencia" y "precedente" no son equiparables en cuanto a su relevancia como fuentes del derecho. Este punto lo aclara de manera suficiente Yepes Arcila al explicarnos que la figura del precedente, propia de los sistemas jurídicos del common law, y la jurisprudencia, propia de los sistemas del civil law, se asemejan en cuanto a que ambas constituyen el resultado de la actividad judicial, pero se diferencian fundamentalmente en que el precedente tiene una función principal dentro del ordenamiento en cuanto a producción normativa, mientras que la jurisprudencia tiene una función residual que consiste en la interpretación que hacen los jueces de normas establecidas por un legislador diferente a ellos mismos (2012, pp. xIV-xv). En otras palabras, el precedente tiene fuerza normativa como fuente del derecho, mientras que la jurisprudencia tiene una fuerza residual o accesoria en tal calidad.

7 Traducción del autor.
Adicionalmente, y una vez plasmada la anterior aclaración, debe precisarse también que la figura del precedente no tiene la misma fuerza en todos los sistemas legales, aunque de acuerdo con MacCormick y Summers la tendencia parece ser a que la distancia entre la fuerza del precedente en los sistemas de derecho civil y del common law se reduzca, pues "el precedente cuenta para mucho en los sistemas legales de derecho civil. La tendencia de estos dos sistemas a converger es un hecho destacado de finales del siglo veinte, aunque aún persisten diferencias, algunas de gran importancia” (1997, p. 2).

Ahora, bien, ¿cómo afecta la seguridad jurídica el respeto que un ordenamiento brinda al precedente judicial?, ¿los jueces en sus decisiones deben estar sometidos a la ley en la misma medida en que lo están con respecto al precedente?, ¿es más importante para la seguridad jurídica la estabilidad en la ley que la estabilidad del precedente? En este campo están las discusiones más relevantes, y por eso haremos algunas anotaciones al respecto.

El precedente judicial permite a los justiciados prever el contenido de las decisiones de los jueces y aclarar el sentido de las normas jurídicas, de tal manera que dicha previsibilidad hace posible la seguridad jurídica. Dicho de otra manera, la principal ventaja de la estabilidad en el precedente judicial es que permite anticipar las consecuencias de la actuación tanto estatal como particular, elemento esencial de la seguridad. En suma, puede decirse que el precedente contribuye a brindar estabilidad y certeza. 
Hanna, haciendo referencia al juez Moschzisker, resume las ventajas del precedente como "certeza, estabilidad, igualdad y predictibilidad" (1957, p. 377). ${ }^{8}$ Kemelmaier de Carlucci concluye también que la jurisprudencia discordante genera inseguridad jurídica, pues interpretaciones diferentes de un mismo órgano jurisdiccional o de diversos órganos generan inseguridad (1998, p. 216), y la jurisprudencia discordante es el inevitable resultado del irrespeto por el precedente judicial. Sin embargo, esa estabilidad que resulta esencial para la seguridad jurídica, según Marinoni se logra no solamente por la estabilidad y respeto al precedente sino también por la estabilidad de las normas jurídicas (2012, p. 257).

Ahora bien, está también la discusión con respecto a la importancia que reviste para la seguridad jurídica la concordancia que debe haber entre el texto y el espíritu de la ley, con la interpretación que de esta efectúan los jueces al momento de aplicarla a un caso concreto. Sin esa armonía, sin esa concordancia, difícilmente puede existir seguridad jurídica. El juez americano Stephen Markman lo resume de manera acertada cuando afirma: "a mí no me convence que la estabilidad de la ley es verdaderamente mejorada por un precedente que lee el texto de la ley para que signifique otra cosa diferente a la que simplemente dice... así como tampoco me convence que la integridad de la ley se vea fortalecida cuando los procesos tradicionales de interpretación son suplantados por las preferencias personales de los jueces" (2003-2004, p.

8 Traducción del autor.
286). ${ }^{9}$ En consecuencia, considera que lo importante y lo que debe primar al momento de fallar no es el precedente sino la ley misma, pues "es la ley la que debe aplicarse de manera consistente... es la ley la que los jueces han jurado cumplir, no el brillo que le ha puesto a la misma un predecesor" (p. 283). ${ }^{10}$

Comparte la anterior postura el juez jamaiquino Patrick Robinson, para quien el juez debe ceñirse a la ley al momento de tomar una decisión y no al precedente judicial. Aunque la independencia judicial debe ser preservada en todo momento y a toda costa, esta independencia "no significa es que los jueces sean libres para decidir los casos de acuerdo con sus propios caprichos o prejuicios. Los jueces están constreñidos por la ley y tienen la responsabilidad de aplicar la ley a los hechos que les han sido presentados a ellos" (2013, p. 616).

Por su parte, Marinoni no está de acuerdo con que la estabilidad de la ley sea el factor fundamental que hace posible la seguridad jurídica. En su criterio, resulta más importante la estabilidad de las decisiones judiciales que el texto mismo de la ley:

La verdad es que el pleno conocimiento del derecho legislado no solo es imposible, pero igualmente, dispensable, para la previsibilidad y para la tutela de la seguridad. Subráyese que el common law, que ciertamente confiere más seguridad jurídica que el civil law, no relaciona la previsibilidad con el conocimiento de las

\footnotetext{
$9 \quad$ Traducción del autor.

10 Traducción del autor.
} 
leyes, pero sí con la previsibilidad de las decisiones del Poder Judicial... Ahora, si la previsibilidad no depende de la norma en la que la acción se funda, pero sí de su interpretación judicial, es evidente que la seguridad jurídica está ligada a la decisión judicial y no a la norma jurídica en abstracto (2012, p. 253).

Como bien anota Markman, la decisión judicial debe tener "consideración por la confianza y los intereses de la gente, quienes han tomado sus decisiones personales y de negocios bajo los parámetros del sistema legal" (2003-2004, p. 284). ${ }^{11}$

Finalmente, Marinoni reconoce como natural que distintos jueces analicen una misma norma de manera diferente, y eso resulta consustancial a la actividad jurisdiccional. Sin embargo, dichas divergencias se deben minimizar en la medida de lo posible para lograr "la protección de la previsibilidad, indispensable al encuentro de la seguridad jurídica" (2012, p. 254).

Como puede verse en este segmento, existen dos amenazas que la doctrina ha identificado como más severas en contra de la seguridad jurídica, aunque, como se aclaró al comienzo, no son las únicas. Desde el punto de vista de la ley, la doctrina ha identificado como amenaza fundamental contra la seguridad jurídica la excesiva cantidad de normas legales y su deficiente redacción, lo cual redunda en que el ciudadano no tenga certeza o claridad con respecto a cuáles son las reglas vigentes. Y desde el punto de vista del precedente judicial, la principal ame-

11 Traducción del autor. naza contra la seguridad jurídica gira alrededor de la incertidumbre en cuanto a cuál debe ser el fundamento de las decisiones judiciales, si el precedente o el texto de las normas legales, así como la estabilidad que pueda presentar dicho precedente en el tiempo.

\section{CONCLUSIONES}

La presente revisión bibliográfica ha tenido la pretensión de dejar sentado el estado del arte en los temas objeto de estudio en cuanto a la seguridad jurídica. Como resultado, ha quedado claro que la seguridad jurídica: (i) es uno de los valores o principios más importantes de un ordenamiento jurídico, pues sin ella no resulta posible la convivencia pacífica entre los ciudadanos, ni posible la planificación o ejecución de un plan de vida individual o colectivo; (ii) es la primera y más importante manifestación de un Estado de derecho bien dispuesto, en razón a que sirve como freno y control al poder del Estado y de sus agentes, lo cual constituye una de las principales justificaciones de obediencia al derecho.

Igualmente, ha quedado establecido que hay un relativo consenso entre los autores en cuanto a que la seguridad jurídica consiste en la certeza y la previsibilidad de la actuación del Estado y de los ciudadanos, así como en la estabilidad del sistema jurídico mismo; que algunos conciben la seguridad jurídica como la seguridad del derecho, mientras otros la entienden como la seguridad a través del derecho; que hay quienes la ven como un valor, mientras otros la consideran 
uno de los principios jurídicos más importantes cuyos alcances tocan todos los demás principios del ordenamiento.

Finalmente, ha quedado al descubierto que la seguridad jurídica tiene muchas amenazas, pero que las dos más serias parecen ser la gran crisis de la ley por su desvalorización como fuente del derecho, y el irrespeto al precedente judicial por parte de los jueces. Existen otras amenazas que pueden llegar a afectar la seguridad jurídica, y la mayoría de ellas tiene su origen en el irrespeto al principio de separación de los poderes por parte de cualquiera de las ramas del poder público.

\section{Bibliografía}

Aarnio, A. y otros. (1997). In N. MacCormick y R. S. Summers (eds.), Interpreting precedents. A comparative study. Hants: Dartmouth Publishing Company Limited.

Alfonso Hostios, L. C. (2009). Inversión extranjera en patrimonios autónomos incentivos tributarios y cambiarios frente al principio de seguridad jurídica. En Ensayos temas de derecho tributario, cambiario, societario, inversión extranjera, comercio internacional y aduanas. Bogotá: Lewin \& Wills Abogados.

Alterini, A. A. (1993). La inseguridad jurídica. Buenos Aires: Abeledo-Perrot.

Álvarez Londoño, L. F. (2011). Seguridad jurídica, estabilidad y equilibrio constitucional. Hacia un derecho eficiente. Bogotá: Pontificia
Universidad Javeriana, Facultad de Ciencias Jurídicas y Grupo Editorial Ibáñez.

Arango Mejía, J. (Octubre, 1994). La tutela y la seguridad jurídica. Quaestiones Iuridicae, 19.

Basedow, J. (1998). La seguridad jurídica en el derecho económico europeo. Un principio jurídico general a la luz de la jurisprudencia en materia de derecho de la competencia. Revista de derecho comercial y de las obligaciones, 1998(31) 289-308.

Bolás, A. (1993). La documentación pública como factor de certeza y protección de los derechos subjetivos en el tráfico mercantil. En La seguridad jurídica y el tráfico mercantil, (pp. 41-70). Madrid: Civitas S. A.

Bravo Arteaga, J. R. (2005). La seguridad jurídica en el derecho tributario colombiano: ideales, valores y principios. Revista de la Academia Colombiana de Jurisprudencia, (329), 11-41.

Carnelutti, F. (1959). Cómo nace el derecho. S. Sentis Melendo y M. Ayerra Redín (Trads.). Buenos Aires: Ediciones Jurídicas EuropaAmérica.

Cayón Galiardo, A. (Diciembre, 1993). Los efectos de las sentencias declarativas de la inconstitucionalidad de las leyes tributarias y la seguridad jurídica. Impuestos, 12.

De Aquino, J. I. (2003). Seguridad jurídica e inversiones extranjeras en Brasil. En I. B. Gómez de la Torre y R. Rivero Ortega (Eds.), El estado de derecho latinoamericano. Integra- 
ción económica y seguridad (pp. 121-144). Salamanca (España): Ediciones Universidad de Salamanca.

De Vivero Arciniegas, F. (Mayo, 2004). La protección de la confianza legítima y su aplicación a la contratación estatal. Revista de Derecho Público, 17.

Echeverry Uruburu, Á. (2006). La constitución de 1991 y el principio de seguridad jurídica. En Colombia: Cuadernillos Avances, 11, 3-15.

Eskridge, W. N. Jr. (1988). Overruling statutory precedents. Faculty Scholarship Series. Paper 3825.

Fisher, D. E. (1965-1967). Precedent. U. Queensland L. J., 5, 421-426.

Fuller, L. L. (1969). The morality of law. (2a ed.). New Haven and London: Yale University Press.

Fundación Tomás Moro. (2007). Diccionario Jurídico Espasa. A. Gallardo (Ed.) Madrid: Espasa-Calpe S. A.

García de Enterría, E. (1999). Justicia y seguridad jurídica en un mundo de leyes desbocadas. Navarra: Aranzadi S. A.

García Manrique, R. (2012). El valor de la seguridad jurídica. Madrid: Iustel.

García Novoa, C. (2000). El principio de seguridad jurídica en materia tributaria. Madrid: Marcial Pons, Ediciones Jurídicas y Sociales S. A.
Garro, A. M. (1988). Eficacia y autoridad del precedente constitucional en América Latina: las lecciones del derecho comparado. Revista española de derecho constitucional, 8(24), 95-134.

Hanna, J. (1957). The role of precedent in judicial decision. Vill, (2), 367.

Hernández Terán, M. (2004). Seguridad jurídica. Análisis, doctrina y jurisprudencia. Guayaquil: Edino.

Kemelmaier de Carlucci, A. (1998). La seguridad jurídica. Revista de Derecho comercial y de las obligaciones, (203), 181-184.

Landes, W. M. y Posner Richard A. (1976). Legal precedent: A theoretical and empirical analysis. J.L \& Econ, 19(2), 249-307.

Lauroba Lacasa, M. E. (Summer, 2003). El principio de seguridad jurídica y la discontinuidad del derecho. Louisiana Law Review, 63(4), 1245-1275.

Leible, S. (1998). Comercio exterior y seguridad jurídica. Revista del derecho comercial y de las obligaciones, 31, 379-476.

López Medina, D. E. (2012). El derecho de los jueces. ( $2^{\mathrm{a}}$ ed.). Bogotá: Legis.

MacCormick, D. N. y Summers, R. S. (Eds.). (1997). Interpreting precedents. A comparative study. Hants: Dartmouth Publishing Company Limited. 
Madariaga Gutiérrez, M. (1993). Seguridad jurídica y administración pública en el siglo XXI. ( $2^{\mathrm{a}}$ ed.). Santiago: Editorial Jurídica de Chile.

Marinoni, L. G. (2012). El precedente en la dimensión de la seguridad jurídica. Ius et Praxis, 18(1), 249-266.

Markman, S. (Spring, 20034). Precedent: Tension between continuity in the law and the perpetuation of wrong decisions. Tex. Rev. of L \& Pol., 8(2), 283.

Mézquita del Cacho, J. L. (1989). Seguridad jurídica y sistema cautelar para su protección preventiva en la esfera privada. Barcelona: Bosch Casa Editorial S. A.

Moral Soriano, L. (2008). Precedents: Reasoning by rules and reasoning by principles. $N$. Ir. Legal Q., 59(43), 33.

Morello, A. M. (1994). El proceso justo. Del garantismo formal a la tutela efectiva de los derechos. Buenos Aires: Librería Editora Platense S.R.L. y Abelardo Perrot S. A.

Motta, Á. A., Suelt Cock, V. y Corrales Sánchez, M. E. (2012). La importancia de la jurisprudencia en Colombia. Bogotá: Giz de Colombia, Cooperación República de Colombia-República Federal Alemana, Consejo Superior de la Judicatura.

Muñoz, I. (1997). Los factores que determinan el desarrollo de la seguridad jurídica en la economía. Contribuciones, 3, 59.
Niblett, A. (February, 2010). Do judges cherry pick precedents to justify extralegal decisions: A statistical examination. Md.L.Rev., 70, 101138.

Novoa, C. G. (2000). El principio de seguridad jurídica en materia tributaria. Madrid: Marcial Pons.

Palma Fernández, J. L. (1997). La seguridad jurídica ante la abundancia de normas. Madrid: Centro de Estudios Políticos y Constitucionales.

Peyrano, J. W. (1998). La seguridad jurídica y el efectivo reconocimiento de derechos: valores de la escala axiológica del proceso civil. Revista del derecho comercial y de las obligaciones, 31(181-184), 395-414.

Radbruch, G. (1959). Filosofía del derecho. (4a ed.). Madrid: Editorial Revista de Derecho Privado.

Rincón Salcedo, J. G. (2011). De la discrecionalidad, la estabilidad jurídica y la eficiencia en la gestión de los recursos humanos. El caso de las fuerzas militares colombianas. En Seguridad jurídica, estabilidad y equilibrio constitucional. I Congreso del Doctorado en Ciencias Jurídicas (pp. 33-58). Bogotá: Pontificia Universidad Javeriana.

Robinson, P. (2014). Judicial independence and the rule of law. En Protecting Humanity: Essays in International Law and Policy in Honour of Navanethem Pillay. Chile: Ed. C. Eboe-Osuji. 
Rojas Gómez, M. E. (2002). La teoría del proceso. Bogotá: Universidad Externado de Colombia.

Sala Sánchez, P. (1994). La seguridad jurídica y la realización judicial del derecho. En Seguridad jurídica y contratación mercantil, (pp. 1746). Madrid: Civitas S. A.

Spriggs, J. F. I. y Hansford, T. G. (2002). The US supreme Court's incorporation and interpretation of precedent. Law \& Soc'y Rev, 36, 139.

Stein, S. (Julio-Septiembre, 1997). Seguridad jurídica en el orden jurídico de la República Federal de Alemania. Contribuciones, (3), 7-31.

Tamayo Jaramillo, J. y Jaramillo Jaramillo, C. I. (2012). El precedente judicial en Colombia: papel y valor asignados a la jurisprudencia. Bogotá: Pontificia Universidad Javeriana, Facultad de Ciencias Jurídicas y Grupo Editorial Ibáñez.

Uprimny, R., Jaramillo, J., Botero, C. y Herreño, L. (2007). Estado de derecho y sentencias judiciales. Seguridad jurídica y garantismo. Bogotá: Instituto Latinoamericano de Servicios Legales Alternativos (ILSA).

Uribe, Á. (1998). ¿En qué consiste una moral moderna? En Convergencia entre ética y política. Bogotá: Siglo del Hombre.
Valdés Sánchez, G. G. (2003). Independencia judicial y seguridad jurídica: ejes de la convivencia. Bogotá: UNO A-Z.

Vigo, R. L. (2012). Constitucionalización y judicialización del derecho. Del Estado de derecho legal al Estado de derecho Constitucional. Bogotá: Pontificia Universidad Javeriana, Facultad de Ciencias Jurídicas y Grupo Editorial Ibáñez.

Villegas, H. B. (Noviembre-Diciembre, 1993). E contenido de la seguridad jurídica. Impuestos, (3).

Weston, A. (2002). A Parctical Companion to Ethics. (Segunda ed.). New York: Oxford University Press.

Wingfield, T. C. (2010). Measuring rule of law. En Rule of Law Handbook: A practitioner's Guide for Judge Advocates.

Yepes Arcila, H. (2012). Prólogo. En J. Tamayo Jaramillo y C. I. Jaramillo J. El precedente judicial en Colombia: papel y valor asignados a la jurisprudencia. Bogotá: Pontificia Universidad Javeriana, Facultad de Ciencias Jurídicas y Grupo Editorial Ibáñez. 